\title{
WHO SAVE LIVES: Clean Your Hands global annual campaign. A call for action: 5 May 2011
}

\author{
C. Kilpatrick • D. Pittet
}

Received: 7 March 2011/Accepted: 21 March 2011/Published online: 12 April 2011

(C) Springer-Verlag 2011

The World Health Organization (WHO) SAVE LIVES: Clean Your Hands was launched in 2009. This global, annual campaign was developed as an extension of the WHO Clean Care is Safer Care programme. It is targeted at healthcare facilities and has the aim of 'Bringing people together to improve and sustain hand hygiene' every 5 May.

WHO's motivation has been, and continues to be, in response to the concerns over the global burden of disease due to healthcare-associated infections (HAI), both in developed and developing countries [1]. Recentlypublished data collated by WHO highlight that, when known, HAI rates are, indeed, markedly higher in developing countries than developed countries, with up to $19 \%$ of patients estimated to acquire an HAI hospitalwide. Surgical site infections are known to be the most frequent in these countries and can occur at rates of up to $25 \%$ of all surgical procedures. For ventilator-associated pneumonia (VAP) and neonatal infections, the rates are equally as alarming. VAP occurs up to 17 times

For full information on WHO SAVE LIVES: Clean Your Hands, visit http://www.who.int/gpsc/5may.

C. Kilpatrick · D. Pittet

Clean Care is Safer Care World Health Organization Patient

Safety Programme, Geneva, Switzerland

D. Pittet $(\square)$

Infection Control Programme and WHO Collaborating Centre on Patient Safety, University of Geneva Hospitals and Faculty of Medicine, 4 Rue Gabrielle Perret-Gentil,

1211 Geneva 14, Switzerland

e-mail: didier.pittet@hcuge.ch more frequently in developing than in developed countries, with an excess mortality rate as high as $27 \%$. Neonatal infections are three to 20 times higher and are responsible for $4-56 \%$ of all deaths in the neonatal period. The costs to healthcare systems are also well recognised, particularly in the developed world [2, 3].

In its first 2 years, WHO SAVE LIVES: Clean Your Hands has, on each 5 May, galvanised unprecedented action, including the receipt of online written commitment from 5,000 healthcare facilities in 2009, subsequently totalling over 11,000 in 2010, well exceeding the 10,000 expectation (see Fig. 1). This corroborates the understanding that hand hygiene practices are seen at the core of addressing HAI, but can still be improved [4].

Actions taken in both 2009 and 2010 demonstrate how eager healthcare workers are to ensure real change is made at the point of care to enhance patient safety and reduce HAI. To begin the move from demonstrating commitment to taking action, in 2010, a global survey of hand hygiene compliance with Moment 1 of the WHO 'My 5 Moments for Hand Hygiene', 'Before touching a patient', was announced by WHO, the first of its kind. Approximately one-third of all healthcare facilities that had already registered for SAVE LIVES: Clean Your Hands took part in this survey and the results have been presented as per the six WHO regions, as well as individual participants receiving feedback on their own data [5].

To build momentum and maintain a global profile on the need for clean hands in healthcare, for 5 May 2011, the aim is clear; 'move from commitment to sustained action on hand hygiene improvement'.

The WHO's call is 'Where do YOU stand on hand hygiene?' and the WHO Hand Hygiene Self-Assessment Framework is being promoted to help the understanding of this. All registered healthcare facilities around the globe 


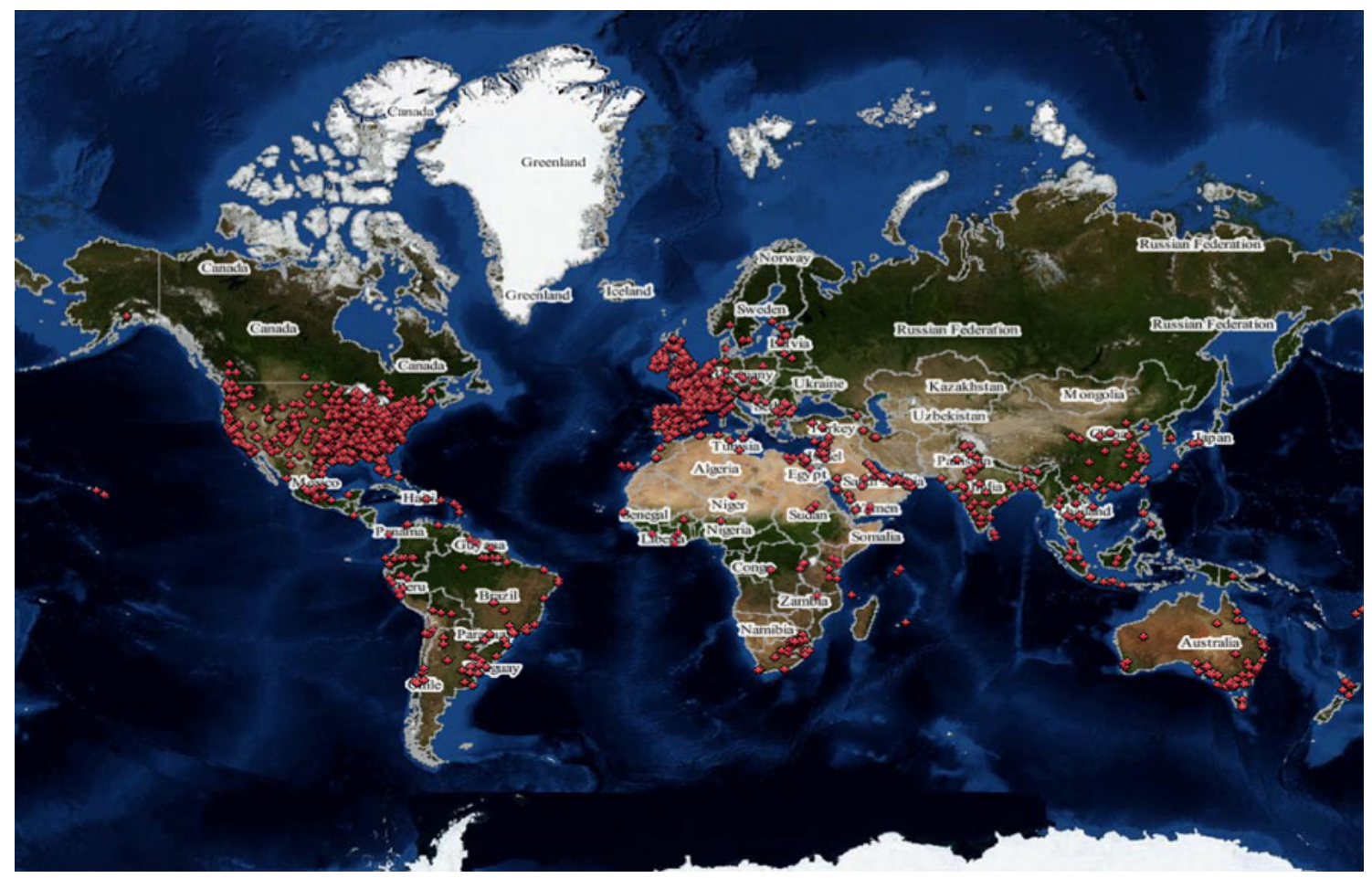

Fig. 1 WHO SAVE LIVES: Clean Your Hands registrations-February 2011: 12,394 registered healthcare facilities from 146 countries corresponding to approximately 7 million healthcare staff and 3 million patient beds

are now being welcomed to participate. The benefits of using the Hand Hygiene Self-Assessment Framework in this regard are clear and are presented on the WHO web pages, where the tool can be downloaded http://www.who. int/gpsc/5may (see the Appendix).

Everyone has a role to play in SAVE LIVES: Clean Your Hands and the WHO's role is one of encouraging widespread action and helping maintain the global profile (see Table 1).
This fledgling campaign has given insight into how those with responsibility for ensuring patient safety through clean hands around the globe react to a WHO call for action and builds on the information available to the WHO through the Clean Care is Safer Care Programme. Launched in 2005, the WHO First Global Patient Safety Challenge: Clean Care is Safer Care aims, overall, to address the global problem of HAI. The main output of this WHO patient safety programme of work

Table 1 Success of SAVE LIVES: Clean Your Hands-the roles of all involved

\begin{tabular}{|c|c|c|}
\hline Healthcare facilities & $\begin{array}{l}\text { Advocates at organisational, national and } \\
\text { regional levels }\end{array}$ & WHO \\
\hline $\begin{array}{l}\text { Commit: register for SAVE LIVES: Clean } \\
\text { Your Hands (if not already done so) } \\
\text { Track progress: use the WHO Hand Hygiene } \\
\text { Self-Assessment Framework } \\
\text { Plan actions: address the components of the } \\
\text { WHO multimodal improvement strategy } \\
\text { and plan the reuse of the framework } \\
\text { Communicate: inform the WHO on using the } \\
\text { Hand Hygiene Self-Assessment Framework } \\
\text { and plan and share other } 5 \text { May } 2011 \\
\text { 'promotional' activities by presenting } \\
\text { information on local web pages }\end{array}$ & $\begin{array}{l}\text { Promote: use of the WHO Framework (and } \\
\text { WHO Hand Hygiene Self-Assessment } \\
\text { Framework tools) for improved and } \\
\text { sustained hand hygiene; SAVE LIVES: } \\
\text { Clean Your Hands commitment through } \\
\text { registering with the WHO; } 5 \text { May } 2011 \\
\text { 'promotional' activities, with features on } \\
\text { local web pages }\end{array}$ & $\begin{array}{l}\text { Encourage: through regular communications, } \\
\text { including a monthly newsletter; availability of } \\
\text { tools; monitoring of Hand Hygiene Self- } \\
\text { Assessment Framework use; gathering of a } \\
\text { sample of completed self-assessments; } \\
\text { announcing registration numbers; issuing new } \\
\text { information on the global burden of HAI; } \\
\text { coordinating a special global teleclass on } 5 \\
\text { May }\end{array}$ \\
\hline
\end{tabular}


has been the WHO Guidelines on Hand Hygiene in Health Care [4] and has, additionally, included the WHO Hand Hygiene Improvement Toolkit that supports implementation of the recommended WHO multimodal improvement strategy. This model was developed within a clinical setting and further validated to ensure applicability to all healthcare settings worldwide, irrespective of resources, through testing in eight pilot sites [4], while wider global activities to allow for widespread awareness raising and cascade training on the implementation of the improvement strategy were additionally undertaken.

Clean Care is Safer Care aims to continue to encourage countries as well as facilities to focus on sustaining hand hygiene improvement, to ensure that hand hygiene stays as a priority on national healthcare agendas. Besides the commitment seen through SAVE LIVES: Clean Your Hands, enthusiasm at the country level has been evident and, indeed, continues to grow. At the end of 2010, 124 Ministries of Health had signed a pledge to address HAIs, which represents almost $90 \%$ of the world's population, and 41 countries/areas had reported the existence of formal hand hygiene campaigns. The WHO has also formed the WHO CleanHandsNet as a network to facilitate progress in such countries, as well as to support the sharing of successes and strategies.

To truly protect our patients, it takes leadership, commitment and a range of actions, from all levels. The WHO's efforts are internationally focused and have demonstrated that the support being provided by this programme to country campaigns in particular is relevant and well received [6]. Along with countries and facilities, this 'top down and bottom up' approach should help bring true ownership to healthcare workers in relation to the prevention of microorganism transmission at the point of patient care and, subsequently, long-term patient safety improvement.

The WHO's call for action for 5 May 2011, and, indeed, every year, is an important step in the global recognition that hand hygiene practices must still be improved and subsequently sustained.

Conflict of interest The authors have declared that no competing interests exist.

\section{Appendix}

Benefits of being part of the WHO's call for 5 May 2011 to understand where you stand on hand hygiene through use of the Hand Hygiene Self-Assessment Framework

Systematically assesses the level of progress on hand hygiene improvement in the areas of infrastructure, resources, commitment and achievements

Identifies the issues requiring particular attention and improvement

Facilitates the development of an action plan for facilities' hand hygiene improvement programmes

Directs you to other WHO Hand Hygiene Improvement Tools to support actions

Allows for structured discussions on results and for the documentation of progress over time

Supports the clear reporting of results, against an action plan, to the directorate of a healthcare facility—allowing for ongoing high-level progress reviews

\section{References}

1. Pittet D, Donaldson L. Clean Care is Safer Care: a worldwide priority. Lancet. 2005;366:1246-7.

2. Allegranzi B, Bagheri Nejad S, Combescure C, Graafmans W, Attar H, Donaldson L, Pittet D. Burden of endemic health-careassociated infection in developing countries: systematic review and meta-analysis. Lancet. 2011;377:228-41.

3. The burden of health care-associated infection worldwide: a summary. Geneva: World Health Organization, 2010. Available online at: http://www.who.int/gpsc/country_work/summary_ 20100430_en.pdf.

4. Guidelines on Hand Hygiene in Health Care. Geneva: World Health Organization, 2009.

5. Hand hygiene moment 1-global observation survey: summary report. Geneva: World Health Organization, 2010. Available online at: http://www.who.int/gpsc/5may/news/ps_moment1_ results_2010_en.pdf.

6. Mathai E, Allegranzi B, Kilpatrick C, Bagheri Nejad S, Graafmans W, Pittet D. Promoting hand hygiene in healthcare through national/subnational campaigns. J Hosp Infect. 2011;77:294-8. doi:10.1016/j.jhin.2010.10.012. 